\title{
Une première épidémie de fièvre à virus Ebola en Afrique de l'Ouest
}

Olivier Reynard ${ }^{1}$, Viktor Volchkov ${ }^{1}$, Christophe Peyrefitte ${ }^{2}$

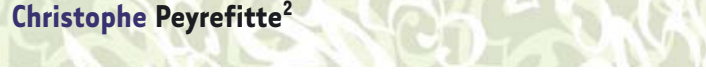

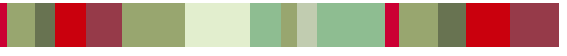

\section{L'épidémie de fièvre hémorragique à virus Ebola : les chiffres}

Depuis quelques mois, une épidémie de fièvre à virus Ebola Zaïre sévit en Guinée et au Libéria. Une récente publication du New England Journal of Medicine a décrit l'émergence de cette nouvelle épidémie [1]. Largement médiatisée dans la presse non spécialisée pour son ampleur, cette épidémie a été observée pour la première fois en Afrique de l'Ouest. Le virus Ebola a été initialement identifié en 1976 dans le nord de la République Démocratique du Congo (ex Zaïre), au cours d'une épidémie de fièvre dont personne ne connaissait la cause. Le taux de mortalité de 88 \% (280 personnes décédées) était l'un des plus élevés pour une maladie d'origine virale [2]. Depuis cette première épidémie, plus d'une trentaine ont été recensées en Afrique totalisant environ 2500 cas [2]. Les virus Ebola appartiennent à la famille des Filoviridae tout comme les virus Marburg et Lloviu. Actuellement, cinq espèces de virus Ebola ont été décrites: Zaïre, Reston, Bundibugyo, Sudan et Taï Forest [3]. Ce sont des virus hautement pathogènes, classés de niveau 4. Ils sont responsables, pour la plupart, de fièvres hémorragiques virales (FHV) le plus souvent fatales chez les primates humains et non humains, lors d'une transmission par contact avec les fluides biologiques [2]. II n'existe à l'heure actuelle aucun traitement thérapeutique ou prophylactique disponible. La question du réservoir reste un élément essentiel de compréhension de l'épidémiologie de la maladie afin de mieux la combattre. L'hypothèse la plus vraisemblable est que les chauves-souris (voire même les cochons pour le virus Ebola Reston) en soient le réservoir [4-6].

Cette nouvelle épidémie a été officiellement déclarée par les autorités guinéennes le 10 mars 2014, en Guinée forestière dans les villes de Guéckédou et Macenta, en
${ }^{1} \mathrm{CIRI}$-Centre International

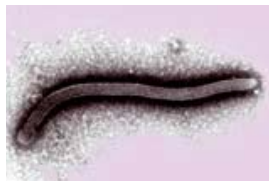
de Recherche en Infectiologie, Inserm U1111 - CNRS UMR5308, Université Lyon 1, ENS de Lyon, 21, avenue Tony Garnier, 69365 Lyon Cedex 07, France. ${ }^{2}$ IRBA-Institut de recherche biomédicale des armées, unité raison de plusieurs de virologie, ERL, Lyon, France. olivier.reynard@inserm.fr cas groupés d'une infection dont l'issue était fatale, caractérisée chez les patients par une forte fièvre et des vomissements associés à une diarrhée sévère [1]. Les praticiens de l'association Médecins sans frontières (MSF) ont été les premiers à avoir été déployés sur l'épicentre de l'épidémie en raison de leur présence à Guéckédou pour lutter contre le paludisme (Figure I).

Devant l'ampleur de la mortalité, les autorités guinéennes ont fait appel au Centre national de référence des fièvres hémorragiques virales (CNR FHV) afin d'établir le diagnostic étiologique de l'infection. Les résultats ont objectivé l'infection des patients par le virus Ebola, entraînant la mise en place d'une équipe européenne dans la zone de l'épicentre de l'épidémie, afin d'être en mesure d'établir le diagnostic biologique localement ${ }^{1}$. Les résultats de l'étude épidémiologique initiale présentés dans l'article de S. Baize et al. [1] ont permis de remonter la chaîne de transmission jusqu'au cas suspect princeps : un enfant décédé le 2 décembre 2013 à Guéckédou. Cette épidémie se serait ensuite propagée le long de la frontière avec le Libéria, puis en direction de la capitale Conakry $(650 \mathrm{~km}$ de l'épicentre), où les premiers cas ont été décrits dès le 27 mars 2014 (37 cas au total). Une équipe de l'Institut Pasteur de Dakar et de la CIBU (cellule d'intervention de biologie d'urgence, Institut Pasteur) a d'ailleurs été installée sur place afin de permettre un diagnostic rapide, essentiel pour la prise en charge et la catégorisation des patients. Il est intéressant de noter qu'en Guinée, les cas se distribuent sur le tracé de la route nationale 1 (Guéckédou-Kissidougou-Dabola-Conakry). Des cas confirmés ont également été identifiés au Libéria, pays voisin

${ }^{1}$ http://www.msf.ch/nos-projets/ce-que-nous-faisons/en-bref/ebola/ 

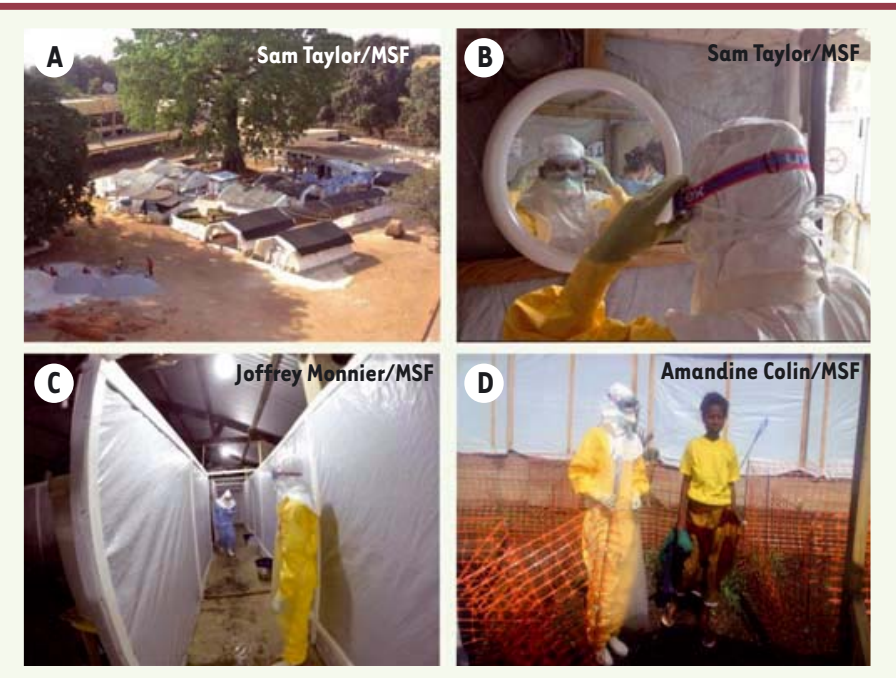

Figure 1. Centre d'isolement de Médecins sans frontières. A, B. La clinique દbola de Médecins sans frontières à Conakry, $C$. Equipement de protection du personnel soignant. $D$. La première patiente guérie et autorisée à quitter la clinique de Guéckédou (๔ Crédit Photo MSF).

(les comtés de Lofa et Margibi sont respectivement à 100 et $450 \mathrm{~km}$ de l'épicentre) dès le 26 mars 2014. Concomitamment sévit au Libéria une épidémie de virus Lassa dans le comté de Margibi, alors que l'on pensait à une nouvelle extension de la zone de circulation du virus Ebola. À l'heure actuelle en Guinée, l'OMS fait état, dans ses derniers bulletins du 11 et 15 juin 2014, d'un total de 351 cas cliniques dont 226 fatals, soit un taux de mortalité de $64 \%$ auxquels viennent s'ajouter une centaine de cas suspects. Au Liberia, 28 cas compatibles avec une infection à virus Ebola ont été identifiés dont certains dans la capitale Monrovia qui compte plus d'un million d'habitant. Récemment, l'épidémie s'est propagée à la Sierra Leone où 138 cas cliniques ont été recensés. Les derniers éléments du suivi épidémiologique font état de très nombreux cas contacts (plus de 1000 en Guinée) ainsi que d'une recrudescence des nouveaux cas cliniques; ceci laisse présager que l'épidémie pourrait encore s'étendre dans les semaines à venir [7]. Ces données viennent confirmer la très grande pathogénicité de ce virus Ebola, un taux de mortalité de $88 \%$ ayant été recensé par le passé [8].

Cette étude de S. Baize et al. [1] a montré que les premiers cas suspects présentaient une fièvre, des diarrhées et des vomissements associés dans certains cas à un syndrome hémorragique. Parmi ces patients, il est à noter qu'une femme enceinte a survécu malgré un avortement spontané. Des cas d'avortement avaient déjà été mentionnés à l'occasion d'autres épidémies à virus Ebola: en particulier celle de 1976 à Yambuku, où $23 \%$ des femmes avaient survécu dans les mêmes conditions, et plus récemment celle de Kikwit en $1995[9,10]$.

\section{Hypothèses sur l'origine du virus Ebola}

Les analyses phylogénétiques obtenues grâce aux séquences génomiques complètes des isolats provenant de trois patients, et présentées dans l'article du New England Journal of Medicine, suggèrent que le virus
Ebola circulant en Guinée pourrait être une sous-espèce du virus Ebola-Zaïre, ce dernier étant génétiquement séparé de toutes les souches de RDC et du Gabon depuis 1976 [1]. Compte tenu de la distance génétique (moins de 0,01 ) et de la valeur élevée de bootstrap ${ }^{2}$ (93\%) [1], deux hypothèses possibles pourraient expliquer la présence de ce virus en Guinée. Soit le virus aurait pu être endémique bien avant l'épidémie, soit il aurait pu être introduit récemment. II est intéressant de souligner que le virus Ebola proche géographiquement de l'épicentre de l'épidémie (moins de $600 \mathrm{~km}$ ) appartient à un sous-type différent: le virus Ebola-Taï forest [11]. Ce virus avait été isolé en 1995 dans le parc du même nom dans le sang périphérique d'une vétérinaire ayant pratiqué une autopsie sur un singe infecté [11]. II est d'ailleurs probable que plusieurs sous-espèces de virus Ebola puissent circuler en même temps en Afrique de l'Ouest. Le rôle joué par les chauves-souris dans l'expansion du virus Ebola est au cœur des recherches actuelles; en particulier, deux études parues en 2010 et 2012 font état de la présence d'anticorps spécifiques du virus Ebola Zaïre dans le sérum de chauves-souris ( $\varepsilon$. helvum, E. franqueti, E. gambianus, H. monstrosus, N. veldkampii) au Ghana, situé à environ 1400 km de l'épicentre de l'épidémie actuelle [12, 13]. Ces études suggèrent que plusieurs espèces de chauves-souris frugivores participent à la circulation des différents virus Ebola. Par ailleurs, l'aire de répartition de ces espèces de chauves-souris englobe très largement celle du virus Ebola et inclut la majorité de l'Afrique sub-saharienne (Figure 2). Il est alors possible de supposer que la zone de circulation $\mathrm{du}$ virus Ebola soit beaucoup plus grande que celle qui est décrite actuellement. En outre, les résultats d'une étude sérologique datant de 1989 ont révélé qu'un taux de séropositivé pour le virus Ebola était de 4,5\% dans un échantillon de 318 patients malgaches, ce qui renforce très largement l'hypothèse d'une grande zone de circulation (Figure 2). Plus récemment, un nouveau genre de filovirus a été génétiquement identifié dans le nord de la péninsule ibérique (le virus Lloviu) [14], ce qui élargit encore la zone de circulation des filovirus. La présence de foyers massifs de virus Ebola Reston (n'étant pas actuellement identifié comme pathogène pour l'homme) en Asie du Sud-Est (Philippines) vient encore conforter l'hypothèse d'une circulation quasi planétaire des filovirus [15]. La question de la zone d'extension maximale des épidémies à virus Ebola est donc à considérer avec un très grand sérieux, d'autant plus que des études ont montré que le virus Ebola Zaïre pouvait s'adapter à un nouvel hôte murin grâce à

${ }^{2}$ La méthode du bootstrap a été proposée par Bradley Efron (1979) comme une alternative aux modèles mathématiques traditionnels dans des problèmes d'inférence complexe en phylogénie génétique. 


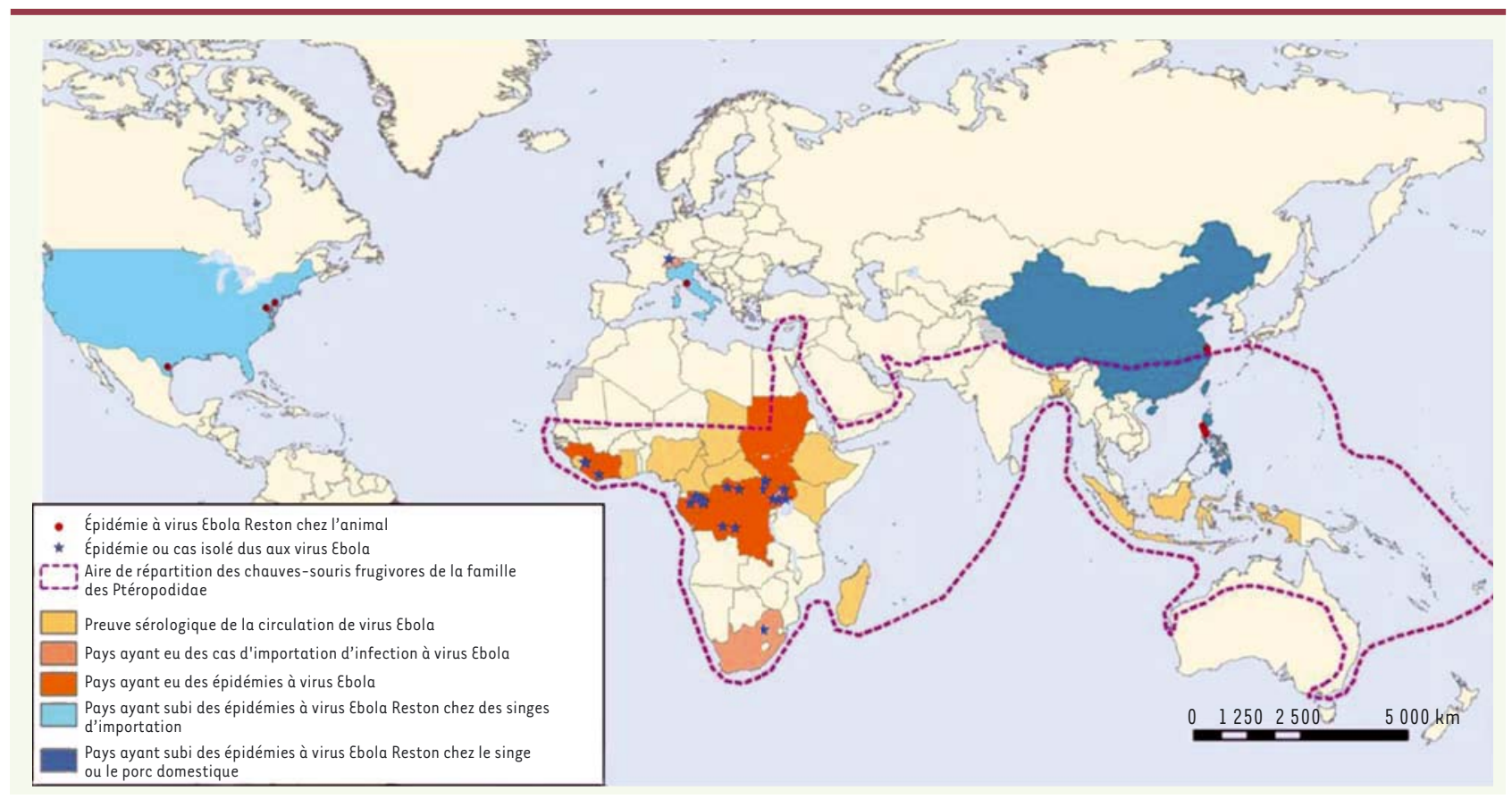

Figure 2. Répartition en 2014 des cas d'importation et des épidémies à virus Ebola. En pointillé, la limite de répartition des chauves-souris frugivores de la famille des ptéropodidae (données WHO, modifiées).

l'acquisition d'une mutation unique dans son génome (1 nucléotide sur 18960 ), ce qui laisse à penser que ce virus pourrait circuler via d'autres espèces que celles classiquement décrites dans la littérature [16]. Les évolutions majeures des activités humaines, conjuguées aux modifications climatiques, constituent pour l'avenir autant de facteurs qui influenceront la zone de circulation des Filovirus Ebola et Marburg.

\section{Conclusions}

L'isolement des patients et la recherche des cas suspects sont les clés pour contrôler l'expansion de l'épidémie de virus Ebola. À l'heure actuelle, l'épidémie de Guinée semble être contenue, en raison des efforts conjugués des acteurs de terrain en matière d'organisation de la surveillance et du contrôle de cette épidémie : ministère guinéen de la Santé, Médecins sans frontières, GOARN (Global Outbreak Alert and Response Network, OMS), Institut Pasteur, laboratoire mobile européen, qui ont permis d'apporter une réponse très précoce.

L'article de S. Baize [1] a permis d'objectiver, pour la première fois en Afrique de l'Ouest, la circulation d'un virus Ebola Zaïre lors d'une épidémie de fièvre hémorragique majeure. Ce travail souligne l'importance et le caractère très actuel d'une meilleure connaissance de l'écologie de ce virus hautement pathogène et en particulier d'une identification de son réservoir. $\diamond$

\section{A first outbreak of Ebola virus in West Africa}

\section{LIENS D'INTÉRÊT}

Les auteurs déclarent n'avoir aucun lien d'intérêt concernant les données publiées dans cet article.

\section{RÉFÉRENCES}

1. Baize $S$, Pannetier D, Oestereich L, et al. Emergence of Zaire Ebola virus disease in Guinea : preliminary report. N Engl J Med 2014 ; 16 avril (online).

2. Kortepeter MG, Bausch DG, Bray M. Basic clinical and laboratory features of filoviral hemorrhagic fever. J Infect Dis 2011 ; 204 (suppl 3) : S810-6.

3. Kuhn JH, Bao Y, Bavari S, et al. Virus nomenclature below the species level: a standardized nomenclature for filovirus strains and variants rescued from cDNA. Arch Virol 2013 ; 159 : 1229-37.

4. Barrette RW, Metwally SA, Rowland JM, et al. Discovery of swine as a host for the Reston Ebola virus. Science 2009 ; 325 : 204-6.

5. Leroy $E M$, Kumulungui $B$, Pourrut $X$, et al. Fruit bats as reservoirs of Ebola virus. Nature $2005 ; 438: 575-6$.

6. Towner JS, Pourrut X, Albarino CG, et al. Marburg virus infection detected in a common African bat. PLoS One 2007 ; 2 : e764.

7. Ebola virus disease, West Africa-update. http://www.who.int/csr/don/2014_06_10_ebola/en/

8. Mahanty S, Bray M. Pathogenesis of filoviral haemorrhagic fevers. Lancet Infect Dis $2004 ; 4: 487-98$.

9. Ebola haemorrhagic fever in Zaire, 1976. Bull World Health Organ 1978 ; 56 : 271-93.

10. Mupapa K, Mukundu W, Bwaka MA, et al. Ebola hemorrhagic fever and pregnancy. J Infect Dis $1999 ; 179$ (suppl 1) : S11-2.

11. Le Guenno B, Formenty P, Wyers M, et al. Isolation and partial characterisation of a new strain of Ebola virus. Lancet 1995 ; 345 : 1271-4.

12. Hayman DT, Emmerich P, Yu M, et al. Long-term survival of an urban fruit bat seropositive for Ebola and Lagos bat viruses. PLoS One 2010 ; 5 : el1978.

13. Hayman DT, Yu M, Crameri G, et al. 2012. Ebola virus antibodies in fruit bats, Ghana, West Africa. Emerg Infect Dis $2012 ; 18$ : 1207-9.

14. Negredo A, Palacios G, Vazquez-Moron S, et al. Discovery of an Ebola viruslike filovirus in Europe. PLoS Pathog $2011 ; 7$ : e1002304.

15. Sayama Y, Demetria C, Saito M, et al. A seroepidemiologic study of Reston Ebola virus in swine in the Philippines. BMC Veterinary Res $2012 ; 8: 82$.

16. Mateo M, Carbonnelle C, Reynard 0 , et al. VP24 is a molecular determinant of Ebola virus virulence in guinea pigs. J Infect Dis 2011 ; 204 (suppl 3) : S1011-20.

\section{TIRÉS À PART}

0 . Reynard 